\title{
Island Vertical Trapezius Myocutaneous Flap Procedure under the Tumescent Technique
}

\author{
O. Papadopoulos ${ }^{\mathrm{a}} \quad$ P. Konofaos ${ }^{\mathrm{b}, \mathrm{c}} \quad$ V. Medvedev ${ }^{\mathrm{a}} \quad$ C. Chrisostomidis ${ }^{\mathrm{a}}$ \\ a Department of Plastic and Reconstructive Surgery, A. Sygros Hospital, Athens, Greece; ${ }^{b}$ Division of \\ Plastic and Reconstructive Surgery, Eastern Virginia Medical School, and ' International Institute of \\ Reconstructive Microsurgery, Norfolk, Va., USA
}

\section{Key Words}

Vertical trapezius myocutaneous flap · Tumescent technique

\begin{abstract}
We describe the application of local anesthesia with intravenous sedation for covering a large defect of the upper back with the use of the island vertical trapezius myocutaneous flap to an 85-year-old male. According to the anesthesiologist, the patient was graded as ASA IV. A $200-\mathrm{ml}$ solution which consisted of $0.75 \mathrm{mg}$ xylocaine, $2 \mathrm{mg}$ adrenaline $(1 / 2,000,000)$ and $10 \mathrm{mmol} / \mathrm{l}$ sodium bicarbonate in a physiologic saline solution was used. The total operating time was about 90 min. During the first postoperative $24 \mathrm{~h}$, the flap pedicle was checked every hour by Doppler. The postoperative course of the patient was uneventful. We believe that in selected cases, when microsurgery is not indicated due to the general medical condition of the patient, the combination of the tumescent technique with sedation and the vertical trapezius myocutaneous flap can be considered a reliable and low-risk procedure.

Copyright $\odot 2007$ S. Karger AG, Basel
\end{abstract}

\section{Introduction}

The vertical trapezius myocutaneous flap (VTMF) was first described in 1979 by Mathes and Nahai [1]. Different types of trapezius myocutaneous flaps have been described. With the exception of free tissue transfer [2], the classic [3] or extended [4, 5] VTMFs are the only reliable flaps that can be used for reconstruction of the head, neck and upper segment of the back.

The aim of this case report is to present the application of local anesthesia with intravenous sedation for covering a large defect of the upper back with the use of the island VTMF.

\section{Case Report}

An 85-year-old Greek male was admitted to the Department of Plastic and Reconstructive Surgery at A. Sygros Hospital due to a recrudescent basal cell carcinoma of the skin at the upper part of the back. The tumor was about $6.5 \times 7.0 \mathrm{~cm}$ large, involving the spinalis cervicis muscle and part of the trapezius muscle (leaving out the cervical vessels). The patient underwent the appropriate preoperative evaluation. According to the anesthesiologist, the patient could not withstand an operation for excision of the tumor mass and covering of the defect under general anesthesia, due to his low ejection fraction $(<25 \%)$, high blood systolic pressure $(>150 \mathrm{~mm} \mathrm{Hg})$ and his chronic obstructive pulmonary disease. Thus, we decided to perform excision of the tumor and cov-

\section{KARGER \\ Fax +41613061234 E-Mail karger@karger.ch} www.karger.com
Petros Konofaos, MD

330 West Brambleton Avenue, Suite

Norfolk, VA 23510 (USA)

Tel. +1 757319 8444, Fax +1 7576252131

E-Mail petros_konofaos@yahoo.com 


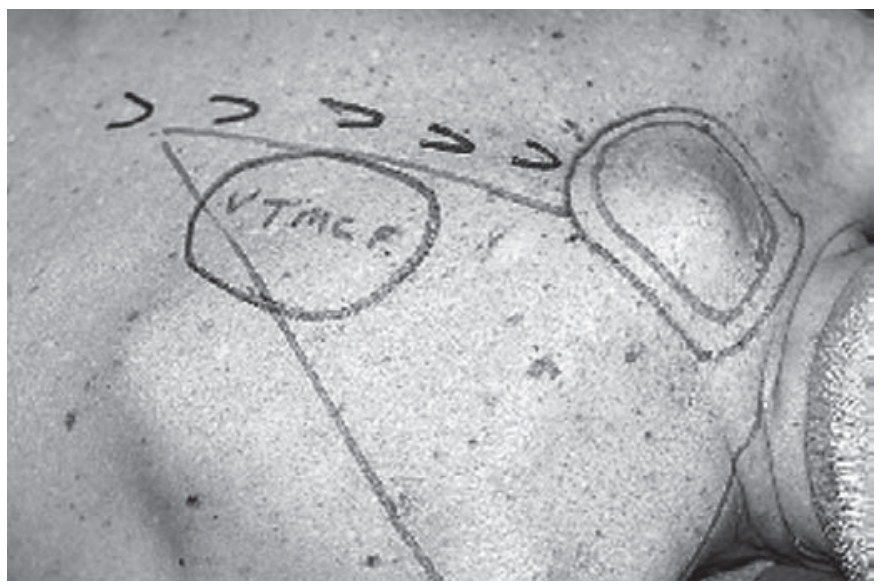

Fig. 1. Design of the recrudescent tumor, excision, and design of the VTMF.

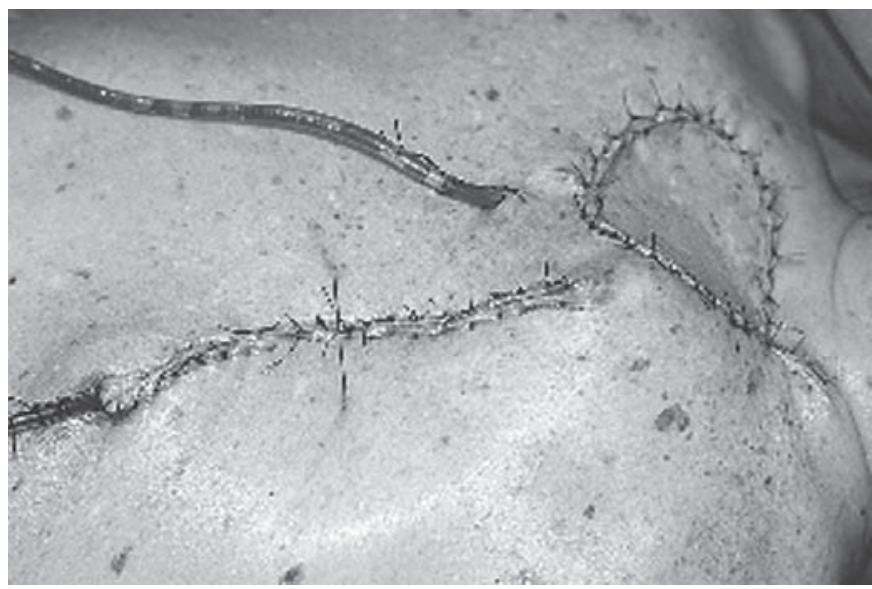

Fig. 3. Perioperative results showing the donor and the recipient site.

ering of the defect under local anesthesia using the island VTMF (fig. 1, 2). The patient was graded as ASA IV.

The operation started with the design of the excision borders and the flap which was essential for the extent of its arc of rotation and its survival. We used Doppler mapping for identification of the flap pedicle, i.e. the descending branch of the transverse cervical vessels. The long axis of the flap was centered between the vertebral column and the medial border of the scapula, along the route of the transverse cervical artery. The tail end of the skin island was at the inferior angle of the scapula. The patient was placed in a semi-prone position on the operating bed due to his general medical condition.

As local anesthesia, we used a $200-\mathrm{ml}$ solution which consisted of $0.75 \mathrm{mg}$ xylocaine, $2 \mathrm{mg}$ adrenaline $(1 / 2,000,000)$ and $10 \mathrm{mmol} / \mathrm{l}$ sodium bicarbonate in a physiologic saline solution. During the operation, the patient was supported by an oxygen apparatus, air duct and Levine tube. The patient also received

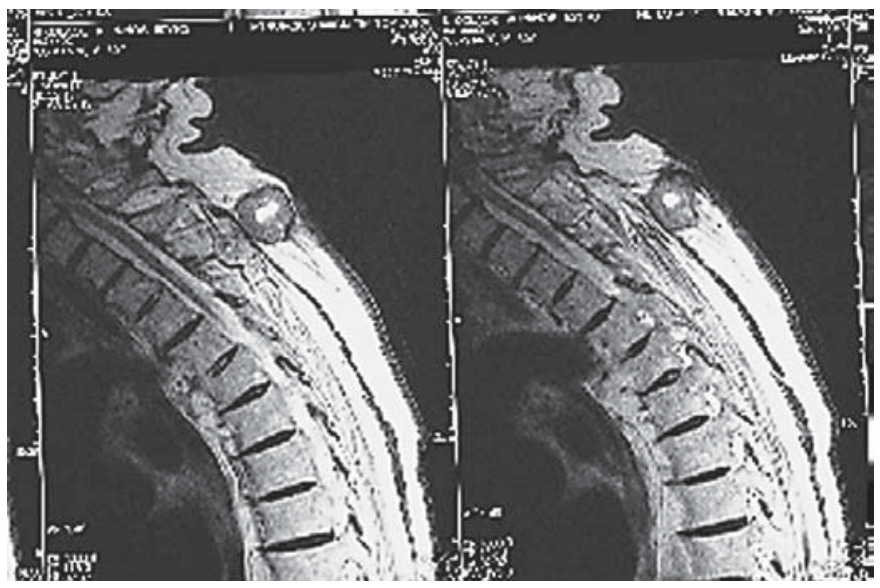

Fig. 2. Location of the tumor in relation to the spinalis cervicis muscle and part of the trapezius muscle.

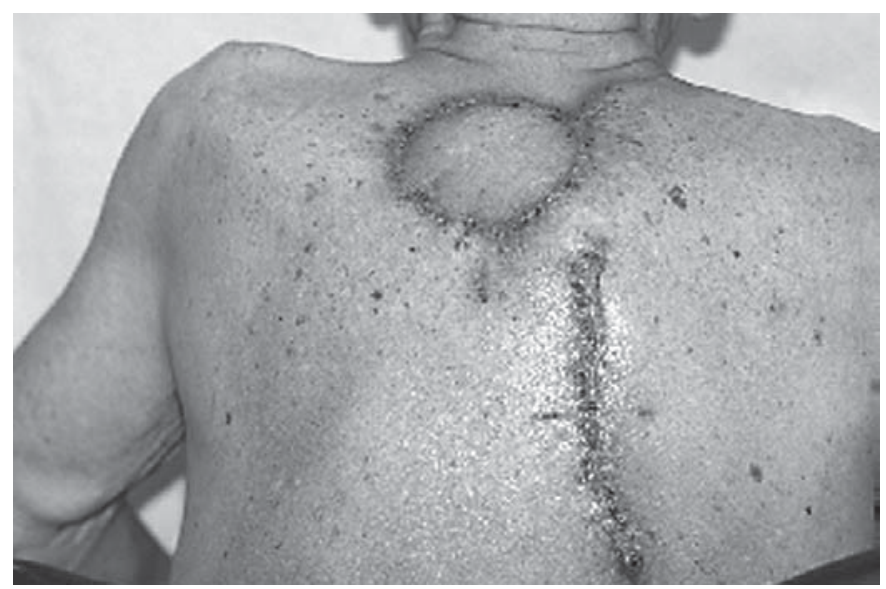

Fig. 4. Short-term postoperative results.

$150 \mathrm{mg}$ fentanyl and $1.5 \mathrm{mg}$ Dormicum. The systolic pressure of the patient was kept above $130 \mathrm{~mm} \mathrm{Hg}$ in order to achieve better perfusion of the flap.

The solution of diluted adrenaline was injected along the selected outlines into the relatively avascular adipose tissue which produced widespread prolonged and profound vasoconstriction and provided adequate analgesia. We performed liposuction in order to avoid unsafe blood levels of local anesthetics.

After excision of the tumor mass, the island VTMF was raised. Flap elevation began with an incision at the middle level of its medial border. Identification of the trapezius muscle was followed by dissection from the lower limit of the flap upwards, leaving the rhomboid muscles in place. The flap was raised as far as the identification and dissection of its pedicle, i.e. the descending branch of the transverse cervical vessels. After complete mobilization of the muscle, the flap was rotated to cover the defect. 
In order to achieve a better surgical field and taking into consideration that the defect of the donor site was approximately 7.5 $\times 7.5 \mathrm{~cm}$, we performed mobilization of the adjacent tissues. The donor site was closed first and the flap was stabilized into the new position (the defect) by stitches which were put between the skin of the defect and the subcutaneous tissue of the flap. A nylon stitch was put into the skin at the route of the flap pedicle (fig. 3 ). The total operating time was about $90 \mathrm{~min}$. During the first postoperative $24 \mathrm{~h}$, the flap pedicle was checked every hour by Doppler. The postoperative course of the patient was uneventful (fig. 4).

\section{Discussion}

An alternative approach to pain control is to apply drugs locally to the peripheral site of origin of the pain. The significant advances in understanding pain-signaling mechanisms and the pathophysiology of pain, which have been achieved in the past decades, permit the application of local anesthetic agents for surgical procedures which are thought to require general anesthesia. This application is very important, especially in cases where the general medical condition of the patient prohibits general anesthesia. Local anesthetic properties are of prime importance for analgesia provision during the surgical procedure.

Klein [6] suggested the tumescent technique in which a $0.05 \%$ lidocaine solution with 1:1,000,000 epinephrine is injected into the subcutaneous plane to facilitate dissection while providing anesthesia and producing vasoconstriction. The advantages of this technique are prolonged local anesthesia, an essentially bloodless field, an improved dissection plane and rapid postoperative recovery. Many authors suggested the use of the tumescent technique for face lift procedures [7-9].

Hellevuo et al. [10] showed that using lidocaine and adrenaline considerably reduces the operating time and blood loss in free transverse rectus abdominal muscle breast reconstruction. The ability of adrenaline-containing solutions to provide vasoconstriction and a bloodless surgical field is considered important. The concentration of 1:2,000,000 adrenaline in local anesthetics is considered optimal for tissue vasoconstriction even though it is not clarified if this vasoconstriction occurs in the small arteries or in the microcirculation distal to the end arteries [11].

Schoen et al. [9] suggested a waiting period of approximately 5-10 min after injection before proceeding with surgical dissection in order to achieve a maximal hemostatic effect. Moreover, using xylocaine with adrenaline before skin incision usually makes it possible to have less bleeding from the operative field which means less time for hemostasis, lower total operating time and fewer transfusions, and thus, fewer risks of possible transfusion-associated complications.

According to the literature [12-14], adding bicarbonate to the solution of xylocaine and adrenaline neutralizes the acidic $\mathrm{pH}$ of adrenaline, which results in an increase in analgesia provision. Warming of the solution before injection has the same effect [15]. We always add bicarbonate and warm the solution of adrenaline and $x y-$ locaine before using it. Infiltrating the incision lines with lidocaine and adrenaline before the incision makes it possible to have more superficial anesthesia and reduces the need for postoperative pain killers. Patients also have easier postoperative recovery, less postoperative pain and a shorter hospital stay. All the above mentioned advantages of the tumescent technique can be applied in the reconstruction of defects after tumor excision. The only limitation is the prolongation of the 'cutting' time, approximately to $20 \mathrm{~min}$, in order to take advantage of the solution.

Reconstruction of the head, neck and upper trunk areas, especially towards the midline, is a challenge due to the limited number of local flaps with adequate bulk for covering the defect which frequently have their blood supply scarified at the excision of the tumor. Selection of the most appropriate flap for reconstruction of these defects is based upon two major criteria: the size and the depth of the defect.

The VTMF is considered by many authors as a reliable solution for the reconstruction of large defects of the head, neck and upper trunk areas $[3-5,16,17]$. The dominant blood supply of the trapezius muscle and its overlying skin below the tip of the scapula is from the dorsal scapular artery $[18,19]$. The dominant supply of the vertical trapezius is from the transverse cervical artery, and the inferior border of the skin flap could be extended to as low as $10-13 \mathrm{~cm}$ below the end of the trapezius muscle fibers, which is $22-24 \mathrm{~cm}$ below the tip of the scapula.

We prefer the elevation of the VTMF from medial to lateral in order to achieve a better layout of the operating field. Our experience indicates that when elevating the flap from medial to lateral, we can clearly descry the vertical part of the trapezius muscle and the vascular pedicle of the transverse cervical artery, leaving out the rhomboid muscle.

The VTMF has multiple advantages. (1) Its pedicle, the transverse cervical vessels, is constant, and anatomical variations are rare. It is long and thin with a diameter of about $1.8 \mathrm{~mm}$, which allows easy transfer of the flap. 
(2) The flap has adequate tissue bulk to cover large tissue defects. (3) It can be used as an osteomyocutaneous unit, if the scapular spine is included. (4) Its arc of rotation is wide, making it useful in reconstruction of the upper face and scalp. (5) The scar at the donor site is acceptable. Depending on the site of the defect, VTMF can be used either as an island or an extended flap. We use the flap as an island flap in defects of the lower face and neck $[4,16]$. In defects of the scalp and upper face, we prefer the staged procedure to avoid the aesthetically unacceptable bulkiness of the muscular pedicle under the skin of the head and neck, all the way up to the cranio-orbital area.
The main disadvantage of the flap is the sacrifice of the trapezius muscle, necessary for complete mobilization, which may result in shoulder drop. Another disadvantage is the need for intraoperative repositioning of the patient, which is done twice.

It is true that free flaps have replaced the VTMF in most cases of reconstruction of the head and neck. However, in selected cases - when microsurgery is not indicated due to the general medical condition of the patient - the combination of the tumescent technique with sedation and the VTMF can be considered a reliable and low-risk procedure.

\section{References}

1 Mathes S, Nahai F: Clinical Atlas of Muscle and Musculocutaneous Flaps. St Louis, Mosby, 1979, p 396.

2 Papadopoulos O, Tsakoniatis N, Georgiou P, Christopoulos A: Surgical treatment of softtissue sarcomas. Ann Plast Surg 1998;41: 106-107.

3 Demergasso F, Piazza MV: Trapezius myocutaneous flap in reconstructive surgery for head and neck cancer: an original technique. Am J Surg 1979;138:533-537.

-4 Papadopoulos O, Tsakoniatis N, Georgiou P, Christopoulos A: Head and neck soft-tissue reconstruction using the vertical trapezius musculocutaneous flap. Ann Plast Surg 1999;42:457-458.

5 Rosen HM: The extended trapezius musculocutaneous flap for cranio-orbital facial reconstruction. Plast Reconstr Surg 1985;75: 318-324.

6 Klein J: The tumescent technique. Dermatol Clin 1990;8:425-437.
Brody GS: The tumescent technique for facelift. Plast Reconstr Surg 1994;94:563.

8 Mottura A: The tumescent technique for face lifts? Plast Reconstr Surg 1995;96:231.

9 Schoen S, Taylor C, Owsley T: Tumescent technique in cervicofacial rhytidectomy. J Oral Maxillofac Surg 1994;52:344.

10 Hellevuo C, Salmi A, Muuronen E: The use of lidocaine with adrenaline reduces blood loss and operating time in free TRAM breast reconstruction. Eur J Plast Surg 2002;25: 243-246.

11 Porter C, Frizelle F: Use of local anesthetic agents among New Zealand plastic surgeons - their practices and philosophies. Med Sci Monit 2000;6:194-197.

12 Christoph RA, Buchanan L, Begalla K, Schwartz S: Pain reduction in local anesthetic administration through $\mathrm{pH}$ buffering. Ann Emerg Med 1988;17:117-120.

13 Orlinsky M, Hudson C, Chan L, Deslauries R: Pain comparison of unbuffered versus buffered lidocaine in local wound infection. J Emerg Med 1992;10:411-415.
14 Amdt KA, Burton C: Minimising the pain of local anesthesia. Plast Reconstr Surg 1983; 72:676-679.

15 Bartfield JM, Lomer PJ, Ford DT, Sternklar P: Buffered lidocaine as a local anesthetic: an investigation of shelf life. Ann Emerg Med 1992;21:16-19.

16 Papadopoulos ON, Chrisostomidis CI, Georgiou PN, et al: Vertical trapezius musculocutaneous flap: a retrospective study. Scand J Plast Reconstr Surg Hand Surg 2005;39:158161.

17 Mathes SJ, Stevenson TR: Reconstruction of posterior neck and skull with vertical trapezius musculocutaneous flap. Am J Surg 1988; 156:248-251.

18 Netterville JL, Wood DE: The lower trapezius flap. Arch Otolaryngol Head Neck Surg 1991;117:73-76.

19 Netterville JL, Panje WR, Maves MD: The trapezius myocutaneous flap. Arch Otolaryngol Head Neck Surg 1987;113:271-281. 